\title{
Visual field (Octopus 1-2-3) in normal subjects divided into homogeneous age-groups
}

\author{
Perimetria computadorizada no Octopus 1-2-3: estudo de uma população normal por \\ faixas etá rias estratificadas
}

\author{
Nassim Calixto ${ }^{1}$ \\ Roberto Márcio de Oliveira Santos ${ }^{2}$ \\ Sebastião Cronemberg'er ${ }^{3}$
}

Trabalho realizado no Serviço de Glaucoma do Hospital São Gerado Hospital das Clínicas - UFMG.

Professor Titular de Oftalmologia da Faculdade de Medicina da Universidade Federal de Minas Gerais - UFMG - Belo Horizonte (MG) - Brasil.

${ }^{2}$ Doutor em Oftalmologia da Faculdade de Medicina da UFMG - Belo Horizonte (MG) - Brasil.

Professor Titular de Oftalmologia da Faculdade de Medicina da UFMG - Belo Horizonte (MG) - Brasil.

Endereçopara correspondência: Nassim Calixto. R. Grão Mogol, 1177 - Belo Horizonte (MG) CEP 30315-600

E-mail: clinicacalixto@veloxmail.com.br

Recebido para publicação em 08.06.2005

Última versão recebida em 22.12.2005

Aprovação em 02.02.2006

Resumo da Tese de Doutorado do Dr. Roberto Márcio de Oliveira Santos apresentada ao Curso de Pós-graduação em Oftalmologia da Faculdade de Medicina da Universidade Federal de Minas Gerais.

Os autores não têm interesse comercial nos produtos e equipamentos utilizados neste estudo.

\begin{tabular}{l} 
ABSTRACT \\
\hline Purpose: To determine the values in decibels of retinal sensitivity within \\
the central 26 degrees of the visual field of normal subjects divided into \\
homogenous age groups using the Octopus 1-2-3; to compare the values \\
of retinal sensitivity we have found with those considered normal in the \\
statistical package obtained by a multicenter study performed in 1994 \\
with Octopus 201 . Methods: 181 subjects divided into 6 homogeneous \\
age groups (10 to 19 yr; 20 to 29 yr; 30 to 39 yr; 40 to 49 yr; 50 to 59 yr and \\
60 year-old or older) were evaluated. Data on visual sensitivity and age, \\
average sensitivity of central and paracentral regions and eccentricity \\
were calculated. Results: The average visual sensitivity of all groups \\
was $26.77 \pm 1.74$ dB. Correlation between visual sensitivity and age \\
evaluated by linear regression was $28.4-0.040 \mathrm{x}$ (age) for the whole \\
sample and $28.7-0.050 \mathrm{x}$ (age) for subjects aged 20 or more. Sensitivity \\
reduction by eccentricity was -0.30 dB/degree for the whole sample and \\
for subjects aged 20 or more. Conclusions: Correlation between retinal \\
sensitivity values and age based on the autoperimeter Octopus 201 \\
(average sensitivity of $31.2-0.064 \mathrm{x}$ age) is different from that found in \\
this study: average sensitivity of $28.4-0.040 \mathrm{x}$ (age) for the whole sample; \\
$28.7-0.050 \mathrm{x}$ (age) for subjects aged 20 or more. Values obtained with the \\
Octopus $1-2-3$ autoperimeter cannot be compared with those by other \\
Octopus models ( 101,201 and 500 ) due to their distinct features.
\end{tabular}

Keywords: Perimetry/instrumentation; Perimetry/statistic and numerical data; Visual fields/physiology; Age groups; Sensory threshold; Aging/physiology

\section{INTRODUCTION}

With the advent of new technologies in the last years, the study of glaucoma had several of its diagnostic tools improved in order to achieve early diagnoses and adequate follow-up of glaucomatous patients.

The clinical aim of a psychophysical test, such as the computerized visual field, is to find or exclude pathological alterations. A prerequisite to recognize pathological changes, therefore, is knowledge on normal patterns. As results of psychophysical tests vary for a single normal subject and also among normal subjects, normal values may only be established based on statistical calculations, which represent sample values in healthy populations being demonstrated by means of averages and standard deviations ${ }^{(1)}$. Considering the fact that the detection of early injuries is particularly important in glaucomatous eyes, one should be cautious about minor changes in normal values ${ }^{(2)}$. 
Reference values for all Octopus autoperimeters were obtained by a multicenter prospective study performed in the European Continent and North America using the Octopus 201 autoperimeter and the program $\mathrm{G} 1^{(3)}$. This sample was not divided into age groups ${ }^{(2,4)}$. Therefore, in the present study, different from previous works, we have analyzed visual fields of Brazilian subjects divided into defined age groups, using the Octopus 1-2-3 autoperimeter. To our knowledge, investigations on visual field according to age groups have not been carried out yet.

The aims of this study were:

1) To determine values of retinal sensitivity in $\mathrm{dB}$ within the central 26 degrees of the visual field for age groups out of 181 normal subjects using the Octopus 1-2-3 autoperimeter;

2) To compare values of retinal sensitivity of these subjects with those considered normal by the statistical package obtained by the multicenter study performed in 1994 with the Octopus 201 autoperimeter $^{(2,4)}$.

\section{PATIENTS AND METHODS}

One hundred and eighty-one subjects, divided into 6 homogeneous age groups as follows: 10 to $19 ; 20$ to $29 ; 30$ to $39 ; 40$ to 49; 50 to 59 to 60 and older, were examined between April 2000 and June 2002. Examinations were carried out in the Glaucoma Service of the Hospital São Geraldo or in the private clinic of one of the authors (RMOS). The project complies with the Research Ethics Committee of the Federal University of Minas Gerais.

After signing an informed consent, the patients had their eyes completely examined. Those who fitted the criteria to be included in the study and presented none of the exclusion criteria, defined for the present study, were submitted to three examinations of computerized visual field selecting one of the eyes through the table of random numbers. The first two examinations were made applying a dynamic strategy for learning purposes and the third, generally a week later, with the normal strategy, program G1X, two phases and eight stages. Results from the third examination were assessed and those presenting reliability indices out of the acceptable values (up to $15 \%$ of false-positive or false-negative responses) were excluded from this study. Inclusion criteria for the present study were: free and clarified consent at the selection visit; minimum age, 10 years; normal eye examination; intraocular pressure (IOP) measured by Goldmann's applanation tonometer equal to or lower than $18 \mathrm{mmHg}$; pupil diameter equal to or higher than three millimeters and availability to accomplish all the examinations scheduled in chronogram. The exclusion criteria were: the presence of systemic diseases such as arterial hypertension requiring three or more drugs or systemic beta-blockers; retinopathy such as hemorrhage, exudates or papilledema; diabetes with or without retinopathy; cardiological changes: history of myocardial infarction and heart failure or reports on use of agonist or adrenergic antagonist drugs; presence of arthritis, cervical arthropathy making perimetry difficult; history of cloroquine use; central nervous systemrelated diseases: report on convulsive crises treated with phenobarbital, migraine in treatment or use of antidepressive drugs; ocular alterations: corrected visual acuity lower than 0.9 in subjects aged between 10-59 and less than 0.8 in those aged 60 or more; dynamic refraction exceeding the limits +3.00 to -3.00 spherical diopters and \pm 2.00 cylindrical diopters; eye lids: ptosis covering any portion of pupil; anisocoria of $1.5 \mathrm{~mm}$ and pupil diameter lower than $3.0 \mathrm{~mm}$; cornea: central opacity, keratoconus, neovascularization or pigment dispersion syndrome; iris: posterior synechiae or any stromal atrophy; crystalline lens: loss of significant transparence; gonioscopy: anterior synechiae to the Schwalbe line; fundus: cup/disc ratio greater than 0.5 ; macula and posterior pole: soft drusen or other pathologies in the macular region.

Data related to the average sensitivity of retina of the 191 subjects were submitted to a statistical test in order to detect outliers or exception values. Based on these data, 10 subjects were excluded from the study because they showed marked visual field changes.

The patients and the examinations that complied with established criteria constituted the sample of the current study: 181 subjects (181 eyes) (Table 1$)$.

For each patient the 59 points of the G1X program were obtained and stored in a specific file and converted into compatible numerical data with an electronic Excel plan of the Convert software. The G1X program is divided into two phases each one with four stages. In the first phase there is a staircase procedure changing the intensity of light stimulus in $4 / 2 / 1 \mathrm{~dB}$. In this phase the mean sensitivity (MS), mean deviation (MD) and loss variance (LV) indices were obtained. In the second phase, starting from the sensitivity obtained in the first phase, the program reexamines the same previously evaluated retinal points, changing the intensity in $2 / 1 \mathrm{~dB}$. In this phase the corrected loss variance (CLV) and short-term fluctuation (SF) indices are determined (Figure 1).

Visual fields of left eyes were analyzed after conversion to the corresponding locations in the right eyes. Considering

\begin{tabular}{|lcccc|}
\hline \multicolumn{2}{|c}{ Table 1. Distribution of patients according to gender and age } \\
Group & $\begin{array}{c}\text { Age group } \\
\text { (years) }\end{array}$ & $\begin{array}{c}\text { Female } \\
\text { Gender }\end{array}$ & Male & Total \\
1 & 10 a 19 & 22 & $\mathbf{n}$ & \\
2 & 20 a 29 & 25 & 6 & 28 \\
3 & 30 a 39 & 15 & 8 & 33 \\
4 & 40 a 49 & 25 & 13 & 28 \\
5 & 50 a 59 & 17 & 7 & 32 \\
6 & $\geq 60$ & 21 & 13 & 30 \\
& Total & 125 & 56 & 30 \\
$n$ & & $(59.01 \%)$ & $(30.99 \%)$ & $(100.00 \%)$ \\
\hline
\end{tabular}


that the programs $\mathrm{G} 1$ and $\mathrm{G} 1 \mathrm{X}$ perform sensitivity correction based on age only for subjects aged 20 or more and, in the present work, an age group ranging from 10 to 19 years was also assessed, statistical analysis, when necessary, was carried out in two ways: for the whole group and for the subjects aged 20 or more to the effect that we could compare with the multicenter study ${ }^{(2,4)}$ and reference data obtained from the Octopus 1-2-3 autoperimeter ${ }^{(3)}$.

For data analysis, the central limit theorem was used. Here, in only two age groups the number of subjects was less than 30 (groups 1 and 3 with 28 subjects). There were 30 or more patients in the other age groups and, therefore, the number of subjects was regarded to be statistically adequate. To assess visual sensitivity averages, Student's $t$ test was used to compare averages between two age groups and variance analysis for three or more groups. When $p$ showed to be lower than 0.05 , one could conclude with $95 \%$ confidence that at least one of the groups showed an average value different from the others. Identification of different groups was carried out by means of
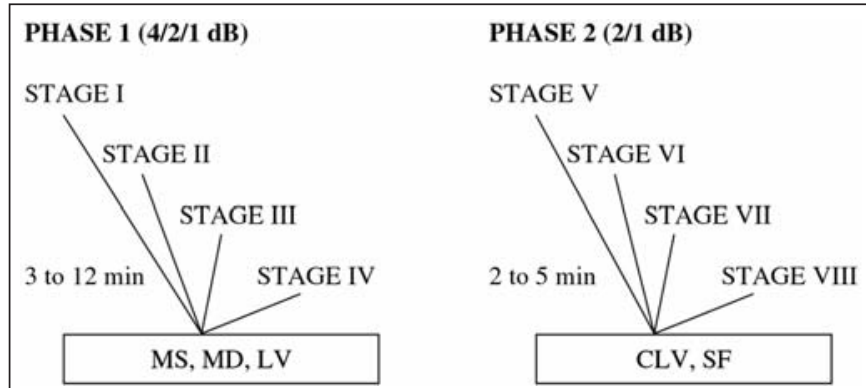

$\mathrm{MS}=$ mean sensitivity; $\mathrm{MD}=$ mean defect; $\mathrm{LV}=$ loss variance $\mathrm{CLV}=$ corrected loss variance; $\mathrm{SF}=$ short fluctuation

Figure 1 - Phases and stages of G1X Program - 59 points tested within the central 26 degrees
Duncan's method of multiple comparisons. Pearson correlation (r) coefficient was used to evaluate the ratio between age and visual sensitivity. Linear regression was used to find the equation that would better represent the variables correlation under study. Determination coefficient $\left(\mathrm{R}^{2}\right)$, in the present study, was a visual sensitivity variation value supported by the regression line, in this case, by the subject's age. The U test (non-parametric) was used in order to compare average sensitivity reduction with age in the central and paracentral regions.

\section{RESULTS}

\section{Sample}

Subjects were from 11 to 87 years old, with average equal to 40 and standard deviation, 17.3. Specific measurements of examination (minimum, maximum, average and standard deviation values) and the respective parameters of confidence (examination length, false-positive and false-negative responses, number of applied stimuli and spherical and cylindrical ametropies) are shown in table 2.

\section{Average sensitivity and age}

Average and standard deviation of mean sensitivity (MS) in both phases, in the 59 tested points with normal strategy, were: $26.77 \mathrm{~dB} \pm 1.74 \mathrm{~dB}$, minimum $21.8 \mathrm{~dB}$ and maximum $30.10 \mathrm{~dB}$. Average and standard deviation of MS in the first and second phases were $27.15 \pm 1.65 \mathrm{~dB}$ and $26.39 \pm$ $1.93 \mathrm{~dB}$, respectively (Table 3). Differences between average values was statistically significant $(\mathrm{p}<0.001)$.

Age and retinal sensitivity ratio were assessed by linear regression. A significant difference was observed $(\mathrm{p}<0.001)$ in average sensitivity between age groups (Table 4) for the whole

\begin{tabular}{|c|c|c|c|c|}
\hline Measurements & Minimum & Maximum & Average & Standard deviation \\
\hline Examination length (min) & 14.00 & 21.30 & 16.17 & 1.35 \\
\hline False-positive (\%) & 0.00 & 15.00 & 1.97 & 3.73 \\
\hline False-negative (\%) & 0.00 & 14.80 & 2.40 & 3.90 \\
\hline Reliability factor & 0.00 & 11.40 & 2.09 & 2.59 \\
\hline Number of stimuli & 398.00 & 524.00 & 436.30 & 26.89 \\
\hline Spherical ametropy & -2.50 & 2.50 & 0.50 & 1.00 \\
\hline Cylindrical ametropy & 0.00 & -2.00 & -0.70 & 0.50 \\
\hline
\end{tabular}

\begin{tabular}{|c|c|c|c|c|c|}
\hline \multirow[b]{2}{*}{ Phase } & \multicolumn{5}{|c|}{ Descriptive measurements } \\
\hline & Minimum & Maximum & Average & Standard deviation & $p$ value* \\
\hline Two phases & 21.80 & 30.10 & 26.77 & 1.74 & \\
\hline First phase & 21.20 & 30.20 & 27.15 & 1.65 & $<0.001$ \\
\hline Second phase & 20.40 & 30.00 & 26.39 & 1.93 & \\
\hline
\end{tabular}


sample using the average sensitivity model of $28.4-0.040 \mathrm{x}$ (age). It has shown that in every decade there was a reduction of $0.4 \mathrm{~dB}\left(\mathrm{R}^{2}=16.5 \%\right.$; $\left.\mathrm{r}=-0.41\right)$. For comparative analysis, a regression test was only used for those aged 20 or more (Figure 2) with the model $28.7-0.050 \mathrm{x}$ (age), that means that in every decade there was a reduction of $0.5 \mathrm{~dB}\left(\mathrm{R}^{2}=14.9 \% ; \mathrm{r}=-0.39\right)$.

\begin{tabular}{|c|c|c|c|c|}
\hline Group & $\begin{array}{l}\text { Age group } \\
\text { (years) }\end{array}$ & Average & $\begin{array}{l}\text { Standard } \\
\text { deviation }\end{array}$ & $\underset{\text { value }^{p}}{p}$ \\
\hline 1 & 10 a 19 & 27.57 & 1.10 & \multirow{7}{*}{$<0.001$} \\
\hline 2 & 20 a 29 & 27.38 & 1.29 & \\
\hline 3 & 30 a 39 & 27.11 & 1.54 & \\
\hline 4 & 40 a 49 & 26.63 & 1.87 & \\
\hline 5 & 50 a 59 & 26.35 & 1.90 & \\
\hline \multirow[t]{2}{*}{6} & 60 and over & 25.59 & 1.90 & \\
\hline & Total & 26.77 & 1.74 & \\
\hline
\end{tabular}

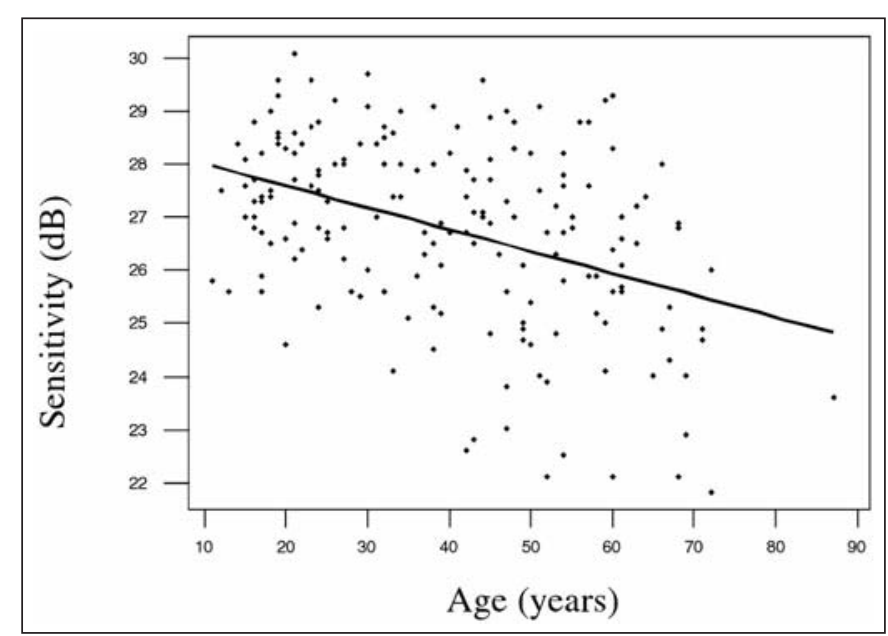

Figure 2 - Retinal sensitivity (dB) and age: linear regression for those aged $\mathbf{2 0}$ or more (great dispersion of values)

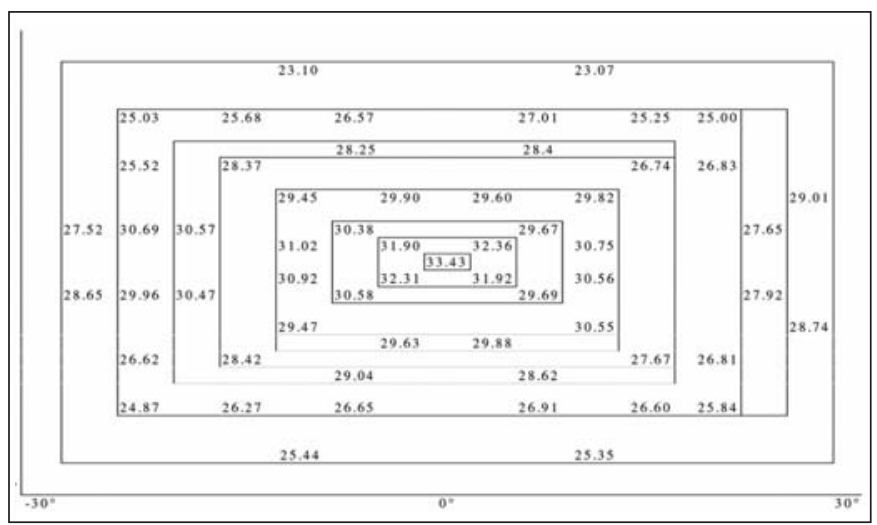

Figure 3 - Values of age-corrected normal thresholds calculated for zero year-old subject (intersection). Data are presented in right eye format; left eye data have been reversed when necessary.
Intersection (point at which the line of linear regression touches the $\mathrm{Y}$ axis corresponding to age 0 ) for the 59 points under study is shown in figure 3 and the reduction of average sensitivity (regression line inclination) per decade is shown in figure 4.

\section{Average sensitivity by regions of the visual field Central and paracentral regions}

Table 5 shows that retinal retinal sensitivity in the paracentral region $\left(11\right.$ to $26^{\circ}$ ) was significantly lower than in the central region $\left(0\right.$ to $\left.10^{\circ}\right)$. Table 6 shows that the reduction of average sensitivity (inclination of regression line) according to age showed no statistical significant difference between paracentral and central regions. A statistically significant higher visual sensitivity was observed in the inferior hemifield when compared with the superior one (Table 7).

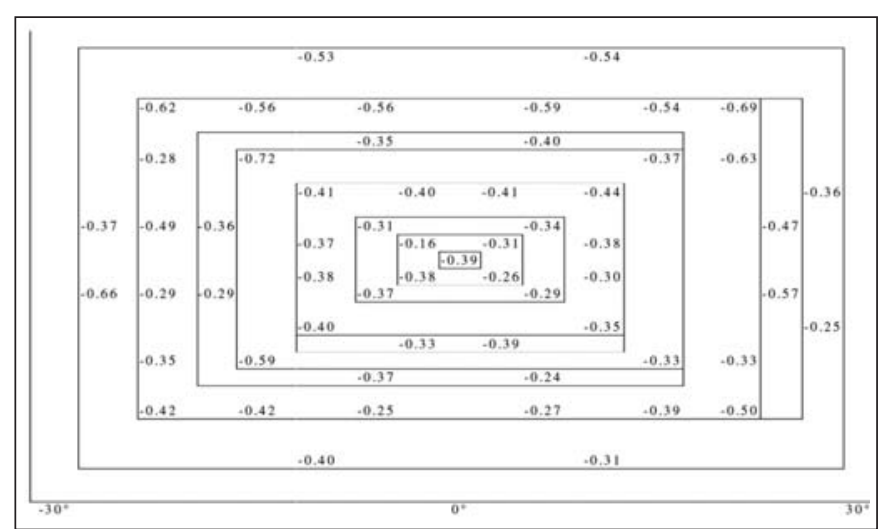

Figure 4 - Pointwise age slopes (loss of sensitivity in decibels per decade) across the tested $26^{\circ}$ field. Data are presented in right eye format; left eye data have been reversed when necessary.

\begin{tabular}{|lccc|}
\hline \multicolumn{4}{|l|}{ Table 5. Retinal sensitivity $(\mathrm{dB})$ of central and paracentral regions } \\
Region & Average & Standard deviation & $\boldsymbol{p}$ value \\
Central & 29.25 & 1.35 & \\
Paracentral & 25.38 & 2.21 & $<0.001$ \\
\hline
\end{tabular}

Table 6. Reduction of average sensitivity (dB) according to the age in central and paracentral regions

\begin{tabular}{|lcccc|} 
Region & $\mathbf{N}^{*}$ & Average & Standard deviation & $\boldsymbol{p}$ value $^{\star \star}$ \\
Central & 21 & -0.0352 & 0.0063 & \\
Paracentral & 38 & -0.0439 & 0.0136 & 0.053 \\
\hline "number of points tested; ${ }^{*}$ U Test & & \\
\hline
\end{tabular}

\begin{tabular}{|lccc|}
\hline \multicolumn{4}{|c|}{ Table 7. Retinal sensitivity $(\mathrm{dB})$ in inferior and superior regions } \\
Region & Average & Standard deviation & $\boldsymbol{p}$ value \\
Superior & 25.94 & 2.41 & \\
Inferior & 26.71 & 2.05 & $<0.001$ \\
\hline
\end{tabular}




\section{Reduction of average sensitivity according to eccentricity}

Reduction of average visual sensitivity at the central point in relation to the reduction of average sensitivity of more peripheral points, for both groups, was $7.83 \mathrm{~dB}$, i.e., $-0.30 \mathrm{~dB} /$ degree of eccentricity.

\section{DISCUSSION}

The choice of the Octopus 1-2-3 autoperimeter was due to its wide use in our country and, besides being produced by an internationally respected and known Swiss company, it has been largely studied as verified by literature data. Among other advantages, it has an accessible price, a compact size and an easily manageable computerized program. In 2002, the Octopus 1-2-3 was substituted by the 301 model. However, this new model presents the same internal and specific characteristics such as size and intensity of stimulus, intensity of maximum stimulus, length of stimulus and background illumination. Thus, our data are also valid for the series of 301 models. Although a previous investigation ${ }^{(5)}$ has assessed computerized visual fields in normal Brazilian subjects through the Humphrey autoperimeter, its methodology using normal subjects but not divided into defined and homogenous age groups - and aims - to determine specificity of full-threshold and SITA strategies using Anderson and GHT criteria - it differs from the present study but is praiseworthy for first determining the values of retinal sensitivity in Brazilian normal subjects.

\section{Average retinal sensitivity and age}

Studies on the correlation between average visual sensitivity and age are traditionally carried out by means of transversal designs ${ }^{(6)}$. Such studies have shown how average visual sensitivity changes in populations according to age, although they do not study subjects throughout aging. Because of economical and circumstantial issues, the present study was also undertaken in a transversal design, including six age groups ranging from 10 to 60 years old or more.

Normality data of the Octopus autoperimeters were obtained through a prospective multicenter study performed in the European Continent and in North America. The Octopus 201 autoperimeter and the program G1 were used for 139 normal subjects who completed the whole chronogram of examinations. Such sample showed an average age of 42.1 years old (median 41.0, standard deviation 14.3, minimum 20 and maximum 70 years old) and it was not divided into age groups ${ }^{(2,4)}$. These data indirectly establish a reduction of $0.065 \mathrm{~dB} /$ year in subjects aged 20 or more for all Octopus models.

It is important to remark that normative data of program G1 has no age correction for subjects aged $<20$. In the present study, such age group had its examinations compared with those from 20-year-old patients, despite showing different average sensitivities (Table 4).

However, in order to compare examinations performed with different autoperimeters, it would be ideal that the following conditions were standardized: a) size and intensity of stimulus; b) intensity of maximum stimulus; c) duration of stimulus; d) background lighting and e) dome radius, which does not happen with all Octopus autoperimeters (Table 8) and others. Significant differences may be observed among Octopus 201, 101 and 1-2-3 autoperimeters regarding background illumination, cupola radius and intensity of maximum stimulus ${ }^{(3)}$. According to Weber's law, visual sensitivity to a luminous stimulus can be described by the equation: $\Delta \mathrm{S}=\Delta \mathrm{I} / \mathrm{I}$, where $\mathrm{S}$ is a measure of sensitivity and $\mathrm{I}$ is a measure of stimulus. In automated perimetry, luminous stimulus is directed to a light background. Under such conditions, the fraction $\Delta \mathrm{I} / \mathrm{I}$ is equivalent to the stimulus intensity divided by the background illumination. Therefore, to make the examination feasible also in normal environmental light conditions, background illumination of the 1-2-3 model was raised to 31.4 asb which also made the manufacturer enhance intensity of maximum stimulus to 4000 asb. Thus, normative data used in Octopus autoperimeters would be specific only for the 201 model and the data obtained here would be specific for the Octopus 1-2-3.

Data provided by the current study are in accordance with those reported by several investigators ${ }^{(2,4,7-10)}$ concerning visual sensitivity significant decrease with age, even using differentiated autoperimeters, strategies, programs and examination conditions. It is important to remark that a study ${ }^{(6)}$ undertaken with normal subjects $(n=562)$ divided into non-homogeneous age groups was not able to show that the non-linear function, with $\mathrm{R}^{2}$ superior to the others, was statistically better than the linear one.

In the present study, the correlation between age and

\begin{tabular}{|c|c|c|c|c|c|}
\hline Parameter & Octopus 101 & Octopus 201 & Octopus 1-2-3 & Humphrey & Dicon \\
\hline Cupola & $\begin{array}{c}\text { Spherical dome } \\
42.5 \mathrm{~cm}\end{array}$ & $\begin{array}{l}\text { Spherical dome } \\
100 \mathrm{~cm}\end{array}$ & $\begin{array}{c}\text { Direct } \\
\text { projection }\end{array}$ & $\begin{array}{c}\text { Dome of } \\
18 \text { to } 30 \mathrm{~cm}\end{array}$ & $\begin{array}{l}\text { Flat } \\
\text { screen }\end{array}$ \\
\hline Background (asb) & 4 & 4 & 31.4 & 31.5 & 31.5 \\
\hline Stimulus duration & Goldmann I to V & Goldmann I to V & Goldmann III to V & Goldmann I a V & LED not standardized \\
\hline Stimulus elapsed time (ms) & 100 variable & 100 variable & 100 variable & 200 & 200 \\
\hline Maximum stimulus (asb) & 1000 & 1000 & 4000 & 10000 & 10000 \\
\hline Normal values & $\begin{array}{l}\text { Per age and } \\
\text { coordinate }\end{array}$ & $\begin{array}{l}\text { Per age and } \\
\text { coordinate }\end{array}$ & $\begin{array}{l}\text { Per age and } \\
\text { coordinate }\end{array}$ & $\begin{array}{l}\text { Per age and } \\
\text { coordinate }\end{array}$ & $\begin{array}{l}\text { Per age and } \\
\text { coordinate }\end{array}$ \\
\hline
\end{tabular}


retinal sensitivity was assessed using linear regression. The following model determined by results has indicated that there was a reduction of $-0.4 \mathrm{~dB} /$ decade: $28.4-0.040 \mathrm{x}$ (age). This model showed $\mathrm{R}^{2}$ value of $16.5 \%$ and $\mathrm{r}=-0.41$, i.e., an inverse and weak correlation between age and visual sensitivity. Program $\mathrm{G} 1$ follows the model: average sensitivity $=31.2-0.064 \mathrm{x}$ (age), a visual sensitivity reduction of $0.64 \mathrm{~dB} / \mathrm{decade}^{(2,4)}$. Nevertheless, in this program, such reduction was only considered for subjects aged over 20 years. Considering this fact, in the present study, a linear regression for age groups over 20 was carried out and the following model was obtained: average sensitivity $=28.7-0.05 \mathrm{x}$ (age), or, a correction of $-0.5 \mathrm{~dB} /$ decade. This model showed values for $\mathrm{R}^{2}=14.9 \%$ and $\mathrm{r}=-0.39$; $\mathrm{a}$ weak and inverse correlation between age and visual sensitivity. When both these formulas are compared, intersection points (line touching Y axis corresponding to age 0 ) are: $31.2 \mathrm{~dB}$ for the multicenter study ${ }^{(2,4)}$ and $28.7 \mathrm{~dB}$ for the present study, with an average sensitivity difference of $2.5 \mathrm{~dB}$. How would such differences (intersection and inclination) affect clinical fields? An examination of a person aged 20 years who showed an average visual sensitivity of $27.5 \mathrm{~dB}$ would be considered to be altered by the Octopus 201 autoperimeter and normal if evaluated based on our study with Octopus 1-2-3. For a patient aged 60 , normal average sensitivity value provided by the program G1 would be $27.36 \mathrm{~dB}$, and here, $25.7 \mathrm{~dB}$; it means a difference of $1.66 \mathrm{~dB}$ (lower than the previous, as line inclination is shorter in this observation). Such differences, when assessed by program G1, overestimate prevalence of campimetric defects mainly in young patients. Aimed at diminishing those differences, program G1 accepts as being normal a deviation of an average sensitivity of $\pm 2.0 \mathrm{~dB}$ for the expected value according to age (mean defect - MD index) and isolated points, as far as $4.0 \mathrm{~dB}$.

One should observe that the equations obtained in the multicenter study ${ }^{(2,4)}$ and in the present paper were obtained from independent groups. For statistical calculation of such difference, the correct way would be to submit the subjects to examinations with both autoperimeters (201 and 1-2-3) and use appropriate statistical analysis to compare paired samples. Instead, this comparison was validated, as normative data of programs G1 and G1X are the same for all models of Octopus autoperimeters and were based on the multicenter study ${ }^{(2,4)}$. It is important to observe that although age affects average visual sensitivity, statistically proved, great part of variability among subjects remains to be explained. Age was used to justify around $25 \%$ variability in a study ${ }^{(6)}$ and $17 \%$ in another ${ }^{(4)}$. Here, age also represented a statistically significant and similar effect $(16.5 \%)$.

\section{Influence of eccentricity}

Reduction in visual sensitivity from the center to the peripheral points is a widely known fact. Manual static perimetry has quantified it in a precise manner. Several investigations ${ }^{(9-11)}$ reported and quantified such reduction using different auto- perimeters. Although the multicenter study ${ }^{(2,4)}$ reported a reduction of $-0.25 \mathrm{~dB} /$ degree from the center to the periphery ( 0 to $26^{\circ}$ ), it does not mention how this calculation was performed. In the current investigation, a reduction of $-0.30 \mathrm{~dB} /$ degree eccentricity in visual sensitivity from the center to periphery was found in subjects aged 20 or more (Tables 5 and $6)$. Results from the multicenter study ${ }^{(2,4)}$, reassessed by the same algorithm, have shown a reduction of $-0.32 \mathrm{~dB} /$ degree, a very close value to that of the present study.

Several investigations ${ }^{(1-2,4,7,10,12)}$ have found a lower visual sensitivity in superior hemifield compared with the inferior one, which is also in agreement with our results (Table 7). It is also remarkable that this difference of visual sensitivity may not be explained by a possible blepharoptosis, once in previous and present studies those subjects had been excluded from the evaluation.

In this study (Table 6) a significant difference was not found regarding reduction of visual sensitivity related to age when central and paracentral regions were compared. These data are in accordance with those from another investigation $^{(4)}$ in which a uniform reduction of sensitivity in the whole visual field has been reported to be correlated with aging, and this was also in accordance with parameters of Octopus autoperimeters that used the same reduction $(-0.65 \mathrm{~dB} /$ decade $)$ in all points under study ${ }^{(3)}$. However, other investigators ${ }^{(9,11)}$ have regarded influence of age on sensitivity depending on eccentricity and vertical hemifield: there was little, but significant, reduction in sensitivity related to age in superior hemifield periphery. Those authors have also admitted that in the absence of significant influence of preretinal factors, neural losses have been associated with variations in sensitivity of visual field due to $\operatorname{aging}^{(12)}$.

Other studies ${ }^{(7,9-11)}$ have indicated that the variation spectrum of interindividual sensitivity related to eccentricity is large. Variability of visual sensitivity threshold basically depends on the patient's age and the site tested ${ }^{(13)}$. These results are in accordance with those obtained by the second author of this study in his clinical experience (data not shown): decrease of sensitivity threshold is much more frequent in the paracentral area than in the central region. For values of a localized defect, corrected according to age, to have the same probability to be abnormal, they should be higher in periphery than in the paracentral region ${ }^{(10)}$. Therefore, another investigation ${ }^{(9)}$ has suggested that perimetric data should be presented in likelihood maps and their significance levels in a pointwise manner.

When average sensitivity related to age is compared, we may notice that, in this study, average height of visual island showed to be lower than expected ${ }^{(2,4)}$. This difference might be due to the use of autoperimeters of different models, to the light color emitted (white in 201 autoperimeter and yellow in the 1-2-3) and, mainly, to the fact that the autoperimeter 1-2-3 does not need dark rooms to carry out examinations. Besides, its background illumination and maximum stimulus intensity 


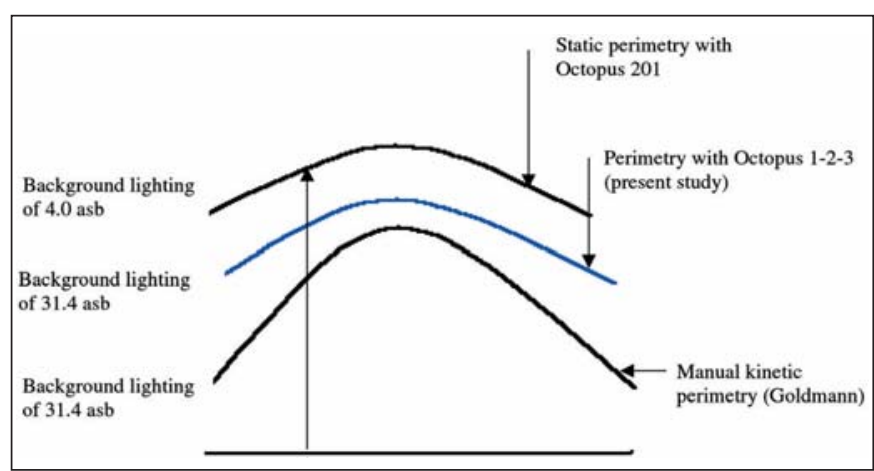

Figure 5 - Representation of background lighting effects over shape and height of vision in static perimetry with Octopus 201, with Octopus 1-2-3 autoperimeter (present study) and manual kinetic perimetry (Goldmann) ${ }^{(15)}$

are raised to 31.4 asb and 4000 asb, respectively. A background illumination of 4.0 asb (used in 201 and 101 autoperimeters) would be ideal to detect small changes in sensitivity and would also provide a more elevated and less steeped visual island (Figure 5), when compared to that obtained by manual devices (kinetic perimetry), using a background illumination of $31.4 \mathrm{asb}^{(9)}$.

However, in the present study, a single and parallel visual island with a lower height (Figure 5) was observed considering that similar values have been found ${ }^{(2,4)}$ when the correlation between sensitivity reduction and eccentricity was studied.

\section{CONCLUSIONS}

The present study on normal subjects, divided into homogeneous age groups and submitted to examination of computerized visual field with Octopus 1-2-3 autoperimeter showed that:

1) average retinal sensitivity for the whole sample was $26.77 \pm 1.74 \mathrm{~dB}$

2) values of retinal sensitivity and its correction according to the age used in Octopus autoperimeters (average sensitivity $=31.2-0.064 \mathrm{x}$ (age) are different from those found here:

a. average sensitivity $=28.4-0.04 \mathrm{x}$ (age) for the whole sample;

b. average sensitivity $=28.7-0.05 \mathrm{x}$ (age) for subjects aged 20 or more;

3) as a consequence of such differences, examinations considered to be normal in the present study, mainly for young subjects, would be incorrectly regarded as altered by using programs of other Octopus autoperimeters.

\section{RESUMO}

Objetivo: Determinar, utilizando o autoperímetro Octopus 1-23 , os valores da sensibilidade retiniana em dB, nos 26 graus centrais do campo visual, em voluntários normais, distribuídos em grupos etários homogêneos. Comparar os valores da sensibilidade retiniana com aqueles considerados normais no pacote estatístico do programa do autoperímetro Octopus 1-23 obtidos por estudo multicêntrico realizado em 1994. Métodos: Avaliaram-se 181 voluntários, distribuídos em seis grupos etários homogêneos: 10 a 19; 20 a 29; 30 a 39; 40 a 49; 50 a 59 e 60 e mais anos. Foram calculados dados relativos à sensibilidade visual e idade, sensibilidade média nas regiões central e paracentral e influência da excentricidade. Resultados: A sensibilidade visual média de todos os grupos foi de $26,77 \mathrm{~dB}$ (desvio-padrão de 1,74 dB). A relação entre sensibilidade visual e idade avaliada pela regressão linear foi de 28,4 - 0,04 x (idade) para toda a amostra e de 28,7 - 0,05 x (idade) para maiores de 19 anos. A redução da sensibilidade com a excentricidade foi de $-0,30 \mathrm{~dB} /$ grau para toda a amostra e de $-0,30 \mathrm{~dB} /$ grau para maiores de 19 anos. Conclusões: Os valores da sensibilidade retiniana encontrados neste estudo: $28,4-0,04 \mathrm{x}$ (idade) para toda a amostra e 28,7-0,05 x (idade) para maiores de 19 anos são diferentes daqueles utilizados nos autoperímetros Octopus e, a rigor, não podem ser comparados aos obtidos nos outros modelos Octopus (101, 201 e 500) em face das suas distintas características.

Descritores: Perimetria/instrumentação; Perimetria/estatística e dados numéricos; Campos visuais/fisiologia; Grupos etários; Limiar sensorial; Envelhecimento/fisiologia

\section{REFERENCES}

1. Haas A, Flammer J, Schneider U. Influence of age on the visual fields of normal subjects. Am J Ophthalmol. 1986;101(2):199-203.

2. Zulauf M, LeBlanc RP, Flammer J. Normal visual fields measured with Octopus-Program G1: II global visual field indices. Graefes Arch Clin Exp Ophthalmol. 1994;232(9):516-22.

3. Interzeag AG. Automated perimetry. In: Interzeag AG. Octopus visual field digest. Switzerland; Schlieren; Octopus; 1998. p.8-12.

4. Zulauf M. Normal visual fields measured with Octopus-Program G1: I differential light sensitivity at individual test locations. Graefes Arch Clin Exp Ophthalmol. 1994;232(9):509-15.

5. Schimiti RB, Avelino RR, Kara-Jose N, Costa VP. Full-threshold versus Swedish Interactive Threshold Algorithm (SITA) in normal individuals undergoing automated perimetry for the first time. Ophthalmology. 2002; 109(11): 2084-92; discussion 2092.

6. Spry PG, Johnson CA. Senescent changes of the normal visual field: an age-old problem. Optom Vis Sci. 2001;78(6):436-41.

7. Brenton RS, Phelps CD. The normal visual field on the Humphrey field analyzer. Ophthalmologica. 1986;193(1-2):56-74.

8. Drance SM, Berry V, Hughes A. Studies on the effects of age on the central and peripheral isopters of the visual field in normal subjects. Am J Ophthalmol. 1967;63(6):1667-72

9. Heijl A, Lindgren G, Olsson J. Normal variability of static perimetric threshold values across the central visual field. Arch Ophthalmol. 1987;105(11):1544-9.

10. Jaffe GJ, Alvarado JA, Juster RP. Age-related changes of the normal visual field. Arch Ophthalmol. 1986;104(7):1021-5.

11. Katz J, Sommer A. Asymmetry and variation in the normal hill of vision. Arch Ophthalmol. 1986;104(1):65-8.

12. Johnson CA, Adams AJ, Lewis RA. Evidence for a neural basis of age-related visual field loss in normal observers. Invest Ophthalmol Vis Sci. 1989; 30(9): 2056-64.

13. Katz J, Sommer A. A longitudinal study of the age-adjusted variability of automated visual fields. Arch Ophthalmol. 1987;105(8):1083-6.

14. Interzeag AG. General concepts and theoretical basis. In: Interzeag AG. Octopus visual field digest. Switzerland; Schilieren: Octopus; 1998. p.19. 